\title{
Erratum to: Bedtime ingestion of hypertension medications reduces the risk of new-onset type 2 diabetes: a randomised controlled trial
}

\author{
Ramón C. Hermida $^{1}$ • Diana E. Ayala ${ }^{1}$ • Artemio Mojón ${ }^{1} \cdot$ José R. Fernández $^{1}$
}

Published online: 6 November 2015

(C) Springer-Verlag Berlin Heidelberg 2015

\section{Erratum to: Diabetologia}

DOI 10.1007/s00125-015-3749-7

New-onset diabetes was not a pre-specified endpoint in the published trial design [1]. However, the authors note that the MAPEC trial was designed to investigate, as major outcomes, total cardiovascular events, major vascular events, new-onset diabetes and new-onset chronic kidney disease.

\section{Reference}

1. Hermida RC, for the MAPEC Study Investigators (2007) Ambulatory blood pressure monitoring in the prediction of cardiovascular events and effects of chronotherapy: rationale and design of the MAPEC Study. Chronobiology International 24:749-775

The online version of the original article can be found at http://dx.doi.org/ 10.1007/s00125-015-3749-7.

\footnotetext{
Ramón C. Hermida
}

rhermida@uvigo.es

1 Bioengineering and Chronobiology Laboratories, E.I.

Telecomunicación, University of Vigo, Campus Universitario,

Vigo, Pontevedra 36310, Spain 